\title{
Gastrointestinal symptoms and autism spectrum disorder: links and risks - a possible new overlap syndrome
}

This article was published in the following Dove Press journal:

Pediatric Health, Medicine and Therapeutics

28 September 2015

Number of times this article has been viewed

\author{
Jolanta Wasilewska \\ Mark Klukowski \\ Department of Pediatrics, \\ Gastroenterology and Allergology, \\ Medical University of Bialystok, \\ Bialystok, Poland
}

Correspondence: Jolanta Wasilewska Department of Pediatrics, Gastroenterology and Allergology, Medical University of Bialystok, Jerzego Waszyngtona Street 17, 15-274 Bialystok, Poland

Tel +48 85745070 I

Fax +4885742384 I

Email jolanta.wasilewska@wp.pl
Abstract: Autism spectrum disorder (ASD) is a genetically determined neurodevelopmental brain disorder presenting with restricted, repetitive patterns of behaviors, interests, and activities, or persistent deficits in social communication and social interaction. ASD is characterized by many different clinical endophenotypes and is potentially linked with certain comorbidities. According to current recommendations, children with ASD are at risk of having alimentary tract disorders - mainly, they are at a greater risk of general gastrointestinal (GI) concerns, constipation, diarrhea, and abdominal pain. GI symptoms may overlap with ASD core symptoms through different mechanisms. These mechanisms include multilevel pathways in the gut-brain axis contributing to alterations in behavior and cognition. Shared pathogenetic factors and pathophysiological mechanisms possibly linking ASD and GI disturbances, as shown by most recent studies, include intestinal inflammation with or without autoimmunity, immunoglobulin E-mediated and/or cell-mediated GI food allergies as well as gluten-related disorders (celiac disease, wheat allergy, non-celiac gluten sensitivity), visceral hypersensitivity linked with functional abdominal pain, and dysautonomia linked with GI dysmotility and gastroesophageal reflux. Dysregulation of the gut microbiome has also been shown to be involved in modulating GI functions with the ability to affect intestinal permeability, mucosal immune function, and intestinal motility and sensitivity. Metabolic activity of the microbiome and dietary components are currently suspected to be associated with alterations in behavior and cognition also in patients with other neurodegenerative diseases. All the above-listed GI factors may contribute to brain dysfunction and neuroinflammation depending upon an individual patient's genetic vulnerability. Due to a possible clinical endophenotype presenting as comorbidity of ASD and GI disorders, we propose treating this situation as an "overlap syndrome". Practical use of the concept of an overlap syndrome of ASD and GI disorders may help in identifying those children with ASD who suffer from an alimentary tract disease. Unexplained worsening of nonverbal behaviors (agitation, anxiety, aggression, self-injury, sleep deprivation) should alert professionals about this possibility. This may shorten the time to diagnosis and treatment commencement, and thereby alleviate both GI and ASD symptoms through reducing pain, stress, or discomfort. Furthermore, this may also protect children against unnecessary dietary experiments and restrictions that have no medical indications. A personalized approach to each patient is necessary. Our understanding of ASDs has come a long way, but further studies and more systematic research are warranted.

Keywords: epigenetics, dysautonomia, food allergy, gluten-related disorders, gut-brain axis, microbiome

\section{Introduction}

Autism spectrum disorder (ASD) is a neurodevelopmental disorder with a strong genetic basis and encompasses various conditions with seemingly different phenotypes. 
ASD is clinically present before the age of 3 years with symptoms concerning mainly two areas which are restricted, repetitive patterns of behaviors, interests, or activities, and persistent deficits in social communication and social interaction. ${ }^{1-3}$ This "dyad", implemented in Diagnostic and Statistical Manual of Mental Disorders (DSM)-5 as of 2013, is a reduction of the previous "triad" outlined in DSM-4. Under the new definition of DSM-5, ASD includes what would have been previously assigned as Asperger's disorder, childhood disintegrative disorder, pervasive developmental disorder not otherwise specified, and autism. ${ }^{4,5}$ The phenotypic variability of ASD also includes different levels of intellectual development/maturation with dysfunctions of cognition and perception (which are present in $50 \%-75 \%$ of patients) correlating with severity of autistic behavior. ${ }^{4}$

The incidence of ASD has been rising in the world in recent years. Epidemiological studies in the USA indicate that in the year 1978,1/10,000 children and adolescents were diagnosed with autism. Ten years later, in 1998, the index was $1 / 250$ children between the ages of 3 years and 10 years, and in 2007, 1/150 children at the age of 8 years. The overall prevalence of ASD in 2010, according to latest data from the Centers for Disease Control and Prevention, was $1 / 68$ children. $^{6-8}$

Greater incidence is found among boys (4:1) ${ }^{6,7}$ The reasons for such a significant rise in the prevalence of ASD are not clear.

Our current understanding of the pathogenesis of this condition takes into account genetics along with the environment playing a role as an epigenetic phenotype trigger. ${ }^{9-12}$ Individualized genetic predispositions aided by trigger factors (infections, toxins, trauma, etc) impair embryogenesis as well as peri- and postnatal development of the child. Maternal genetic factors as well as environmental factors affecting the mother before and during pregnancy also seem to play a role in the pathogenesis of ASD. ${ }^{13}$ The genetic architecture of autism has proven to be complex and heterogeneous as shown by studies of cytogenetics, linkage, association, whole-genome linkage or association, and whole-genome or exome sequencing. ${ }^{14,15}$ A complex, multigene model of inheritance implicates the interactions of several genes with most being involved in neurodevelopmental processes (neuronal synaptogenesis, neurotransmitter transformation, neurometabolic conditions, lipid metabolism, and mitochondrial dysfunction). ${ }^{12,16-18}$ Candidate genes include, among others, MeCP2 (Xq28; Rett syndrome), HOXA-1 (7p15.3) and HOXB-1 (7q21.32; embryonal development of the rhombencephalon), EN2 (7q36.3; developmental regulation of the cerebellum), FOXP-2 (7q31.1; speech disorder), WNT2 (7q31-33; fetal development and social deficits), 5-HTT (17q11.1-q12; hyperserotonemia), GABRA3 (15q11-q13; GABAergic neurotransmission), OXTR 2 (3p26.2; decreased serum oxytocin levels), ASL (22q13.1q13.2; impairment of purine biosynthesis), and PTEN (macrocephaly, tumor growth).,16,19-22 Other mono-genetic disorders, such as fragile $\mathrm{X}$ syndrome, tuberous sclerosis, Down's syndrome, phenylketonuria, neurofibromatosis type I, or Angelman syndrome, are found in $10 \%-15 \%$ of patients with ASD. ${ }^{23}$ Newer and newer genetic testing techniques and technologies are being used to investigate ASD and to develop a screening test which could help identify and diagnose ASD at a much earlier age than what is currently possible. ${ }^{24,25}$

How autism is viewed has changed greatly since its first description in 1943 by Leo Kanner. ${ }^{26}$ What was once viewed as an untreatable disease solely concerning the brain is now considered a dysfunction of the central nervous system (CNS) with accompanying disorders of the body in general as well as different organs/systems such as the immunological system or digestive tract. ${ }^{27-29}$ Genetic polymorphism is associated with variability of the clinical presentation of ASD and with comorbid problems. Comorbidity is common, and $>70 \%$ of affected individuals have other concurrent conditions such as epilepsy (30\%), gastrointestinal (GI) problems $(9 \%-70 \%)$, immunodysregulation (38\%), or sleep disorders $(50 \%-80 \%){ }^{14}$ There is no consensus so far concerning how the GI tract is implicated in the pathophysiology of ASD. A search within the Cochrane Library (keywords being autism, gastrointestinal, and diet) resulted in but a few randomized studies. Controlled research studies/trials are evidently needed. This area of medicine gives rise to many questions of which a majority are still waiting for precise and definitive answers. ${ }^{30}$ This paper addresses the possible links between autism and GI disorders.

\section{Clinical symptoms of digestive tract diseases in children with ASD}

Clinical manifestation of digestive tract diseases in children with ASD may differ as compared to children with typical development, and the diagnosis of a GI disorder in children may be more difficult and delayed in time. Subjective symptoms such as pain, discomfort, heartburn, or nausea are very difficult to assess and interpret because of core ASD symptoms such as difficulties in verbal and nonverbal communication as well as an altered perception of pain. ${ }^{30,31}$

The frequency of GI tract symptoms in children with ASD ranges from $9 \%$ to $84 \%$ depending on the method 
(retrospective and prospective studies) compared with 9\%-37\% for children without ASD..$^{30,32-36}$ A study by Koves et al observed clinical symptoms from the GI tract in $84.1 \%$ of children with ASD compared to $31.2 \%$ of children from a control population (where participants studied included siblings).${ }^{37}$ However, a study by Black et al, based on a review of hospital documents, showed that GI tract diseases were diagnosed equally frequent in children with ASD and in a control population ( $9 \%$ vs $9 \%$ ). ${ }^{32}$ A summary of individual studies using meta-analysis indicates that children with ASD have a greater risk of GI symptoms than those without ASD. ${ }^{31}$ In a systematic search involving 15 studies and 2,215 children with ASD published in 2014 by McElhanon et al, four clinical variables (general GI concerns, diarrhea, constipation, and abdominal pain) met the six study thresholds for inclusion in the analysis. ${ }^{31}$ The main results of the meta-analysis showed that children with ASD, in contrast to comparison groups, experienced significantly more general GI symptoms (odds ratio $[\mathrm{OR}] 4.42$ ), higher rates of diarrhea (OR 3.63), constipation (OR 3.86), and abdominal pain (OR 2.45).

Most common GI symptoms include overproduction of intestinal gasses/flatulence (60\%), bloating (38\%), abdominal pain (378\%), diarrhea (28\%), burping/belching (25\%), gastroesophageal reflux symptoms (16\%), and constipation $(10 \%)$ (Figure 1).

Although diarrhea occurred as the second most common GI symptom in terms of frequency, the definition of diarrhea varied among the included studies, and as such, these results should be viewed with caution. A standardized tool such as the visual Bristol Stool Scale (for a more detailed, consistent examination of possible GI symptoms such as diarrhea and constipation) is recommended to assess GI issues among children with ASD. ${ }^{31}$

Functional constipation without an underlying pathophysiological cause has been suggested to be present in most individuals with ASD. ${ }^{31} \mathrm{~A}$ study by Afzal et al noted moderate-to-severe constipation in $36 \%$ of children with ASD compared to $9 \%$ in a control population. ${ }^{38} \mathrm{Absent}$ or delayed acquisition of bowel training secondary to difficulty with sensory stimuli, sensory processing, and motor problems may lead to altered GI motility and defecation physiology. Increased intestinal transit time may also result from a high intake of processed food and a lack of fiber-containing fruits and vegetables as a result of severe food selectivity. ${ }^{30,31}$ Increased intake of refined food products in children with ASD has led to parents reporting worsening of behavioral and GI symptoms. Symptoms such as stomach pains, bloating, or increased flatulence may potentially be explained by

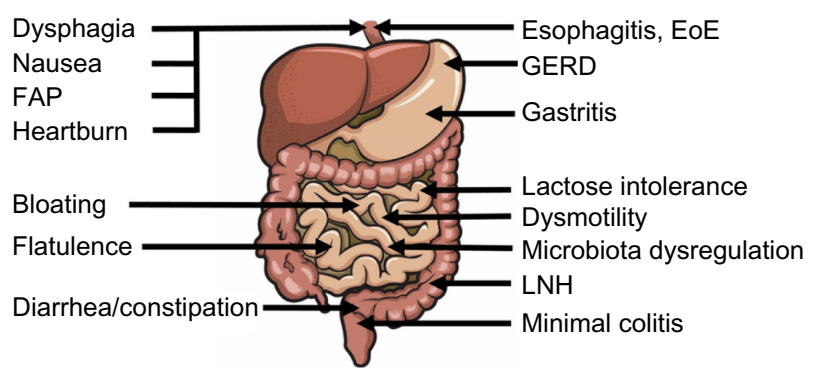

Figure I GI symptoms (left side) and GI disorders (right side) described in children with autism spectrum disorder.

Abbreviations: GI, gastrointestinal; FAP, functional abdominal pain; EoE, eosinophilic esophagitis; GERD, gastroesophageal reflux disease; LNH, lymphonodular hyperplasia.

the overdosing of carbohydrates or enzyme deficiencies of the mucosal membrane responsible for symptoms of food intolerance. Common examples include lactose intolerance, or intolerance to excess fermentable oligo- and disaccharides, monosaccharides, and polyols (FODMAPs) or lactulose. ${ }^{39}$ A list of FODMAPS includes fructans, galactans, fructose, and polyols that are contained in several foodstuffs, including wheat, vegetables, and milk derivatives. ${ }^{40}$ Decreased disaccharidase activity (ie, of lactase, maltase, sucrose glucoamylase, palatinase) associated with functional GI abnormalities was reported in children with autism; however, pancreatic enzymes (amylase, lipase, trypsin, chymotrypsin, carboxypeptidase) did not show a reduction in their activity. ${ }^{15,37,41}$ According to current guidelines, as a first step toward a diagnosis of lactose intolerance, empiric trials of lactase supplementation or dietary restriction of lactose may be considered, in the proper clinical context, before referral to a gastrologist or allergologist. ${ }^{30}$ Congenital predispositions (enzyme defects) and acquired conditions (inflammation of the bowel, intestinal microbial imbalance, or antibiotic treatment side effects) are being reported as causes of lactose intolerance in children with autism. Abdominal pain without underlying abnormal laboratory results or diagnostic imaging is classified as functional abdominal pain (FAP). FAP is linked with hyperalgesia, a type of visceral hypersensitivity to pain sensation. Brain dysfunction may be involved in visceral hypersensitivity as shown by changes in cerebral blood flow during visceral stimulation measured using positron emission tomography, functional magnetic resonance imaging, or single-photon emission computed tomography. ${ }^{42}$

GI problems including feeding problems, dysphagia, nausea, bloating, profound constipation, or diarrhea can reflect functional GI dysmotility (oropharyngeal, esophageal, and bowel dysmotility). These problems as well as FAP can be considered as symptoms of dysautonomia. ${ }^{43}$ The enteric nervous system, described as a "second brain", is a part of the 
autonomic nervous system (ANS) that directly controls the GI system being involved in gut motility, local secretion, and absorption. ${ }^{14}$ Dysautonomia is the disorder of the ANS associated with several diseases, also with autism, but often misdiagnosed and left untreated. ${ }^{44}$ Dysautonomia encompasses abnormal reflex adaptive reactions of control mechanisms in the brain and/or peripheral distribution of the sympathetic and parasympathetic nervous systems. It is hypothesized that limbic system control of the ANS is affected, especially damage to the amygdala (eg, by seizures). ${ }^{45}$ In children with autism, dysautonomia may manifest in many ways: it may be expressed in behaviors such as "hand flapping" or usage of peripheral vision which may be explained as attempts to avoid "unpleasant autonomic sensations" caused by stimulation of visual pathways that disturb sympathetic/parasympathetic homeostasis.

\section{Association between GI disorders and behavior in children with ASD}

The presence of GI disorders in children with ASD poses the question about a possible association between GI disorders and severity of ASD symptoms. Behavior characteristics hypothesized to be expressions of GI problems are common in children with ASD. Facial grimacing, teeth gritting, excessive chewing (of food or items) belong to frequently observed facial expressions of GI symptoms in children with autism. Accompanying vocal behaviors such as sobbing, screaming, or delayed echolalia may also be present. Motor behaviors such as the child placing pressure on the stomach with their own hands or objects, including chairs or tables, may be associated with the abdominal area and are commonly reported by parents and/or caregivers. Such behaviors may be collectively described as abdominal behaviors. Facial expressions and abdominal behaviors may be present as separate entities or coexist with general motor behaviors. General motor behaviors typical for this group of children include self injuries, increased repetitive/stereotypic movements, unusual posturing, or tapping/twitching. Stomach pain or abdominal discomfort in children with ASD may be indicative of motoric excitation which in turn may have an effect on the general state of the child expressed as irritability, oppositional behavior, or sleep disturbances. ${ }^{30}$ Children with abdominal pain are more likely to present with these psychological disorders, anxiety, behavioral problems, or other psychological symptoms. FAP or discomfort in individuals with ASD may be expressed by various vocal and motor behaviors as listed in a consensus report. ${ }^{30}$
Associations between GI symptoms and ASD symptoms have been analyzed in previous studies. Maenner et al state that there are no associations between the presence of GI problems and two of the hypothesized behaviors characterized in patients with ASD: stereotypic/repetitive behaviors and self-injurious behaviors. ${ }^{46}$ In a study by Gorrindo et al, GI dysfunction was significantly associated with sleep disorders and food intolerance but not with irritability or aggressiveness. ${ }^{47}$ In their study, the most common type of GI disorder in children with ASD (85.0\%) was functional constipation and was significantly associated with language impairment. Associations between behavioral problems and GI symptoms were also studied among children with varying subtypes of ASD (ie, high-functioning autism, atypical autism with delayed neurodevelopment). ${ }^{33}$ In 95 children with high-functioning autism and intelligence quotient (IQ) scores $>80$, a majority (61\%) had at least one reported GI symptom. Children with and without GI problems did not differ in autism symptom severity, adaptive behavior, or total internalizing or externalizing problem scores. However, participants with GI problems had significantly higher levels of affective problems. ${ }^{48}$ According to Mouridsen et al, children diagnosed with atypical autism and with an IQ $<70$ are at higher risk of having hospital-diagnosed GI problems than those with an IQ $>70$. Overall, children with atypical autism had about the same frequency of gastric, intestinal, and hepatic diseases as controls. ${ }^{49}$ Furthermore, Smith et al confirmed previously reported findings of an increased incidence of bowel symptoms in children with autism and other developmental and neurological disorders than in healthy children. ${ }^{50}$

Sleep problems are integral components of both the GI system and ASD. Extradigestive symptoms of the alimentary tract include difficulty falling sleep and difficulty staying asleep and have been found in 44\%-83\% of children with ASD. ${ }^{41,51}$ Horvath and Perman reported disturbed sleep and night-time awakening in $52 \%$ of children with ASD who had GI symptoms (vs 7\% of age-matched healthy siblings; $P<0.001)$. Children with ASD who had reflux esophagitis exhibited unexplained irritability more frequently (43\%) than those who did not (13\%). ${ }^{37}$ These observations lead to the conclusion that monitoring of sleep quality may be useful during evaluation of treatment effectiveness in GI disorders in children with ASD. Sleep deprivation may have significant health consequences and may worsen cognitive function by exerting an inhibitory action on the proliferation of neurons in the CNS in children with ASD. Neuroendocrine imbalances caused by sleep disorders are comparable to consequences of chronic exposure to stress. The effects of long-term sleep 
deprivation include inhibition of neurogenesis in the dentate gyrus of the hippocampus with dependent increases in circulating levels of adrenal corticosteroids. ${ }^{52}$ These aspects should not be ignored, and treatment of GI disorders leading to improvement of sleep quality may prove to be beneficial for a child with ASD and may also serve as an indirect argument linking GI disorders and ASD.

\section{Diagnostic evaluation of $\mathbf{G I}$ disorders in children with ASD}

The diagnostic evaluation of GI disorders with behavioral manifestations in patients with ASD can be very complex. ${ }^{53}$ Diagnostic evaluations of GI disorders include a medical history, physical examination, laboratory tests, imaging/ radiological studies, functional studies, and endoscopy. Many authors agree that aggressive diagnostic procedures should be judiciously applied in children with autism. In light of this, less invasive methods are recommended before any planned hospitalizations (such as a diagnostic trial with a proton pump inhibitor in gastroesophageal reflux disease before resorting to a $\mathrm{pH}$-meter or an osmotic laxative such as polyethylene glycol 3350 in cases involving constipation). A consensus report recommends that the initial diagnostic evaluations of GI symptoms and disorders in individuals with ASD be chosen dependent on the type of symptoms (Table 1). ${ }^{53}$

\section{Endoscopic and pathological findings in children with ASD}

Endoscopy, although not a first-line approach to each child with ASD, may have high diagnostic value and be crucial for therapy in certain individuals. ${ }^{30}$ Results of upper and lower endoscopy in children with ASD show that all levels of the GI tract, from the esophagus to the colon/rectum, may be affected. Esophagogastroduodenoscopy results reported by Koves et al showed reflux esophagitis in $69 \%$, chronic gastritis in $42 \%$, and chronic duodenitis with Paneth cell hypertrophy in $67 \%$ of patients. ${ }^{15}$ Results of colonoscopy studies showed ileocolitis and subtle mucosal inflammatory infiltrates of the small and large intestines as common histopathological findings in children with ASD and GI symptoms. ${ }^{54,55} \mathrm{~A}$ lowgrade chronic inflammation of the intestinal mucosa and a GI mucosal molecular profile that overlapped significantly with prodromal phases of inflammatory bowel disease (IBD) have been diagnosed in some children with ASD. ${ }^{56}$ In comparison to IBD, there were no inflammatory markers present in the stool. Fernell et al, studying two independent indicators of IBD, the concentration of nitric oxide in the rectum and calprotectin levels in the feces, are of the
Table I Initial diagnostic procedures for children with autism spectrum disorder depending on clinical GI disorders

\begin{tabular}{|c|c|}
\hline Clinical GI manifestation & Initial diagnostic procedure \\
\hline General Gl symptoms & Abdominal radiograph \\
\hline Gastroesophageal reflux & $\begin{array}{l}\text { Diagnostic trial with a proton pump } \\
\text { inhibitor for } 2-4 \text { weeks } \\
\text { Diet revision/avoiding reflux - } \\
\text { provocative foods/habits } \\
\text { Modification of body sleep position }\end{array}$ \\
\hline Constipation & $\begin{array}{l}\text { Diagnostic trial of polyethylene } \\
\text { glycol (PEG 3350) for } 4 \text { weeks } \\
\text { Diet supplementation with fruits, } \\
\text { fiber, sufficient fluids } \\
\text { Increases/modifications of routines } \\
\text { for sleep and toilet time }\end{array}$ \\
\hline Lactose intolerance & Hydrogen breath test \\
\hline Diarrhea & $\begin{array}{l}\text { Stool analysis for occult blood, } \\
\text { enteric pathogens, ova/parasites } \\
\text { (Giardia or Cryptosporidium), } \\
\text { Clostridium difficile }\end{array}$ \\
\hline Chronic diarrhea, aggression, pain & $\begin{array}{l}\text { Esophagogastroduodenoscopy, } \\
\text { colonoscopy (with biopsy) }\end{array}$ \\
\hline
\end{tabular}

Note: Data from Buie et al. ${ }^{30}$

Abbreviation: $\mathrm{Gl}$, gastrointestinal.

opinion that there is no evidence linking autism with active colitis. ${ }^{57}$ Although a low-grade chronic inflammation of the intestinal mucosa is suggested in some cases, the existence of a GI abnormality specific solely to persons with ASD (ie, "autistic enterocolitis") has not been established. ${ }^{30}$ Similarly, lymphonodular hyperplasia (LNH) on the mucosa of the lower GI tract described in some children with autism is a nonspecific reactive sign, common in other clinical situations in children without autism. ${ }^{57}$ This condition may be the result of long-term retention of intestinal contents (constipation), local infections, parasitic infestations, and chronic exposure to food allergens but may also occur in healthy children. ${ }^{58}$ Scandinavian authors described regression of LNH in children with cow's milk protein allergy after treatment with an elimination diet (milk-free). ${ }^{59}$ Therefore, LNH found in children with ASD may be considered as a secondary response of the intestinal mucosa to food proteins.

\section{Immune-mediated GI food allergies}

GI food allergies are a spectrum of disorders that result from adverse immune responses to dietary antigens. Immunologic GI reactions to dietary proteins are classified as immunoglobulin (Ig) E mediated, non-IgE mediated, or mixed (Table 2). ${ }^{60-62}$

A diagnosis of an immuno-based inflammatory process in the alimentary tract serves as a biological basis to implement a therapeutic elimination diet in accordance with current guidelines for diagnosing food allergy. ${ }^{61-63}$ 
The diagnosis of IgE-mediated food allergy is based on a patient's history, skin prick tests, and/or serum allergen-specific IgE, or if available, on molecular-based allergy diagnostics using purified natural or recombinant allergenic molecules (allergen components) instead of allergen extracts. ${ }^{64}$ The diagnosis of a non-IgE-mediated allergy characterized by nonspecific symptoms is frequently delayed because of insufficient definitive diagnostic biomarkers; however, atopy patch tests with foods may be useful in same cases. An oral food challenge (OFC) is recommended to establish a definitive diagnosis. Amelioration or resolution of symptoms resulting from an elimination diet and relapse of symptoms during an OFC are now accepted as indications for continuation of diet therapy. OFC results should be monitored and reassessed periodically.

IgE-mediated reactions and mast cell activation could contribute to immune and neuroinflammatory abnormalities in patients with ASD ${ }^{65}$ Diet-related intestinal histopathological findings in children with ASD were observed by Ashwood et al.$^{66}$ The researchers found that children with autism treated with an elimination diet (without gluten or casein) had a significantly smaller number of eosinophils in inflammatory bowel infiltrates compared with a group of children with autism not treated with an elimination diet. Eosinophils in inflammatory infiltrates of the mucosa are a component of allergic esophagitis and allergic gastroenteritis, and IgE-mediated and/or cell-mediated chronic inflammatory disorders ${ }^{67}$ Eosinophilic esophagitis has been defined as a clinicopathologic disorder characterized by symptoms related to esophageal dysfunction and pathologically related to eosinophil-predominant inflam-

Table 2 Classification of immune-mediated gastrointestinal food allergies

\begin{tabular}{|c|c|c|}
\hline IgE mediated & $\begin{array}{l}\text { IgE mediated and/ } \\
\text { or cell mediated }\end{array}$ & Cell mediated \\
\hline $\begin{array}{l}\text { Gastrointestinal } \\
\text { anaphylaxis }\end{array}$ & $\begin{array}{l}\text { Allergic eosinophilic } \\
\text { esophagitis }\end{array}$ & $\begin{array}{l}\text { Food protein-induced } \\
\text { enteropathy - celiac } \\
\text { disease (gluten- } \\
\text { sensitive enteropathy) }\end{array}$ \\
\hline \multirow[t]{2}{*}{$\begin{array}{l}\text { Pollen-food allergy } \\
\text { syndrome (oral } \\
\text { allergy syndrome) }\end{array}$} & $\begin{array}{l}\text { Allergic eosinophilic } \\
\text { gastroenteritis }\end{array}$ & $\begin{array}{l}\text { Food protein-induced } \\
\text { enterocolitis syndrome } \\
\text { Food protein-induced } \\
\text { proctitis/proctocolitis } \\
\text { syndrome }\end{array}$ \\
\hline & Main trigger food & \\
\hline \multirow[t]{2}{*}{$\begin{array}{l}\text { Cow's milk, egg, } \\
\text { soy, wheat nuts, } \\
\text { fish, shellfish, fruits } \\
\text { vegetables }\end{array}$} & & Cow's milk, soy, rice \\
\hline & Final diagnosis & \\
\hline \multicolumn{3}{|c|}{ Oral food challenge test with a suspected causal food } \\
\hline
\end{tabular}

Note: Data from these studies. ${ }^{60-62}$

Abbreviation: IgE, immunoglobulin $\mathrm{E}$. mation. ${ }^{68}$ Clinically, the disease can present in children with characteristic symptoms such as dysphagia or food impaction but may also present with various nonspecific symptoms such as abdominal pain, vomiting, reflux-related symptoms, and failure to thrive in young children. An allergic etiology of eosinophilic inflammation has been strongly suggested in a majority of patients with evidence of food or aeroallergen hypersensitivity where treatment included the avoidance of specific foods and airborne allergens. ${ }^{69}$ Three elimination diets have been developed for patients with eosinophilic esophagitis: amino acid-based formula, targeted elimination diet, and empiric elimination diet. ${ }^{67}$

There are currently no conclusive studies confirming that food allergy is more prevalent in children with ASD than in the general population, and recommendations aimed for the general population are accepted. However, the prevalence of GI food allergies may be underestimated because they can be difficult to diagnose even based on endoscopic and histopathological findings. Additionally, endoscopy with anesthesia is not recommended to routinely diagnose food allergy in children with ASD. The exceptions include diagnosis of celiac disease (CD; gluten-sensitive enteropathy) for which this diagnostic approach is strongly recommended.

\section{Gluten-related immune- mediated disorders}

Gluten-related disorders may present with different clinical outcomes and include autoimmune forms (CD, gluten ataxia, and dermatitis herpetiformis), allergy (wheat allergy [WA]) and non-autoimmune, nonallergic disorders (non-celiac gluten sensitivity [NCGS]). ${ }^{39,70} \mathrm{CD}$ is an immune-mediated enteropathy triggered by the ingestion of gluten-containing grains in genetically susceptible individuals. Tissue transglutaminase 2 (TG2) is the primary autoantigen of $\mathrm{CD}$, and anti-tissue TG2 antibodies are used as a serological marker of $\mathrm{CD}^{40}$ The frequency of ASD coexisting with $\mathrm{CD}$ or other reactions to gluten such as NCGS or WA is unknown. In a study by Koves et al, serological testing for CD turned out negative in 400 patients with ASD. ${ }^{15}$ However, in a recent study, Buie points out that with the high prevalence of both autism and $\mathrm{CD}$ (one in 133 individuals), one should expect that in a certain number of people, these two will coexist simultaneously. ${ }^{71}$ Similarly, Klein et al also draw attention to endophenotypes of autism which present with $\mathrm{CD} .{ }^{72} \mathrm{~A}$ study by Lau et al showed increased immune reactivity to gluten (IgG anti-gliadin antibody) in a subset of children with autism with GI symptoms. ${ }^{73}$ The levels of other CD-specific serologic markers, that is, antibodies to deamidated gliadin 
peptides and anti-tissue TG2, did not differ between patients and controls. An association between increased anti-gliadin antibodies and the presence of HLA-DQ2 and/or HLA-DQ8 was not observed. The authors concluded that this immune reactivity to gluten was by a mechanism which appeared to be distinct from that in CD.

Gluten immune-mediated disorders differ in serologic profile depending on the target organ. Organ-specific gluten reactions involve immune responses toward other TG isoforms including TG3 (epidermal TG expressed in the skin, linked with dermatitis herpetiformis) and TG6 (expressed in the brain, linked with gluten ataxia). ${ }^{74}$ It is suggested that TG activity is involved in molecular mechanisms responsible for the pathogenesis of neurodegenerative diseases. ${ }^{75}$ Increased prevalence of TG6 antibodies was found in sera from schizophrenia patients by Cascella et al. ${ }^{76}$ The authors emphasize that as TG6 is primarily expressed in the brain, serum TG6 IgA antibodies represent a marker of neuroinflammation.

Given the above-mentioned studies, one may pose the question if the pathophysiology of neuroinflammation in autism may be linked with gluten by a TG6 isoform, especially in those children with evidence of immune dysregulation and abnormalities of intestinal permeability. This issue remains to be resolved.

Gluten-related disorders include gluten sensitivity (NCGS) characterized by intestinal and extra-intestinal symptoms related to the ingestion of gluten-containing food in subjects who are not affected with either CD or WA. ${ }^{40}$ NCGS presents with typical GI symptoms such as abdominal pain and chronic diarrhea and other extra-intestinal manifestations. Several studies suggested a relationship between NCGS and neuropsychiatric disorders (autism, schizophrenia). ${ }^{40}$

At present, the knowledge on gluten-related disorders in autism is preliminary, and more research is required to develop criteria for identifying subgroups of children with autism who would benefit from a gluten-free diet.

\section{Hypothesis of intestinal barrier integrity impairment}

Leaky gut syndrome as a sign of enteropathy in children with ASD has been discussed by many and confirmed by some authors. ${ }^{77}$ The intestinal barrier is multi-structured and involved in epithelial cell integrity, epithelial transcellular and paracellular permeability, innate immune response, and mucus production. Mucosal immune cells constitute approximately $70 \%$ of the immune cells within the body, and dysfunction in these cells may result in systemic consequences. ${ }^{54}$ Gut-associated lymphoid tissue is a component of mucosa-associated lymphoid tissue. Decreased mucosal immunity may predispose to neuroimmune abnormalities and increased autoimmune responses, especially in children with a positive family history of autoimmunity. ${ }^{14,78,79}$ Only one layer of intestinal epithelial cells (epithelium) separate the contents of the intestinal lumen and access to a number of immune cells in the lamina propria of the mucosa and internal environment of the body. Tightness between epithelial cells depends on intricate connections located on the lateral surface of the cell membrane. ${ }^{80}$ The three main parts of this complex are the following: first, tight junctions which allow for close contact between cell membranes by way of numerous proteins (occludins, claudins, junction adhesion molecules); second, adherens junctions with dynamic properties, thanks to the activity of contracting actin microfilaments; and third, desmosomes - acting as singlepoint connections with mechanical functions. ${ }^{80}$ Increased intestinal permeability may be genetically determined as in the case of IBDs but may also result from inflammation or chronic emotional stress. ${ }^{81,82}$

Increased permeability of the intestinal barrier has been described in $43 \%-76 \%$ of children with ASD both with and without GI symptoms. ${ }^{37,83}$ The leaky gut hypothesis was investigated by Navarro et al in a randomized double-blind, placebo-controlled study on the effects of gluten and milk on intestinal permeability and behavior in children with ASD over a period of 4 weeks. ${ }^{84}$ The study, although underpowered to show small differences, did not support an association between dietary gluten/milk, intestinal permeability, and behavioral changes in subjects with ASD. The evidence of abnormal GI permeability in individuals with ASD is still limited, and prospective studies should be performed to determine the role of abnormal permeability in ASDs. ${ }^{30}$

\section{Preclinical evidence of gut microbiota effects on the brain and the "missing microbiota hypothesis" Renaissance of the gut microbiota}

In 1909, Kendall wrote that the alimentary tract is the perfect incubator providing an appropriate temperature and a steady supply of nutrition for intestinal flora which in turn may affect the general health state of the host. ${ }^{85}$ This observation is currently undergoing a certain renaissance. Studies with gnotobiotic animals (specifically germ-free [GF] mice) are providing much information on the microbiome's influence on the host organism. GF mice lacking 
a microbiome are characterized by a high susceptibility to infection, decreased activity of digestive enzymes, decreased production of cytokines, small variance in Igs, smaller body mass than mice raised in normal conditions, no possibility to induce obesity through a specific diet, and reduced social interaction. ${ }^{86}$ Although these experimental studies may not be extrapolated to a human population, they provide, however, incentive to further study the microbiota in humans. To date, there is rapidly increasing evidence of host-microbe interaction at virtually all levels of complexity, ranging from direct cell-to-cell communication to extensive systemic signaling involving various organs and organ systems, including the CNS. As such, the discovery that different microbial compositions are associated with alterations in behavior and cognition has significantly contributed to establishing the microbiota-gut-brain axis as an extension of the well-accepted concept of the gut-brain axis. ${ }^{87}$ The influence of gut and microbiota on human health is notably studied in patients with autoimmune diseases and those diagnosed with neuropsychiatric disorders, including autism. ${ }^{88-91}$

\section{How does the gut talk to the brain?}

The gut and brain are closely informed about each other. Bidirectional gut-brain communication involves different pathways and elements of the gut connectome (enteric neural network). Afferent, gut-brain, signaling involves the enteroendocrine system, cytokines, sensory epithelial cells, and intestinal microbiota (Figure 2).

Efferent, brain-gut, signaling includes neuroendocrine and autonomic regulation. ${ }^{86}$ This gut-brain axis modulates the body's metabolism and behavior by taking part in the regulation of appetite and energy homeostasis, stress response, emotions and attitude, learning and memory, and response to pain. ${ }^{92}$

\section{The homology between the gut-blood barrier and blood-brain barrier}

The homology between the gut-blood barrier (GBB) and blood-brain barrier (BBB) may play an important role in the multipotent communication between the gut and brain. The $\mathrm{BBB}$, as a selective permeability barrier separating circulating blood from brain extracellular fluid in the CNS, plays an important role in gut-brain communication. Its function is analogous to that of the GBB and also exhibits similar anatomical features such as being formed by brain endothelial cells connected by tight junctions. The homology between the GBB and BBB includes increased permeability resulting

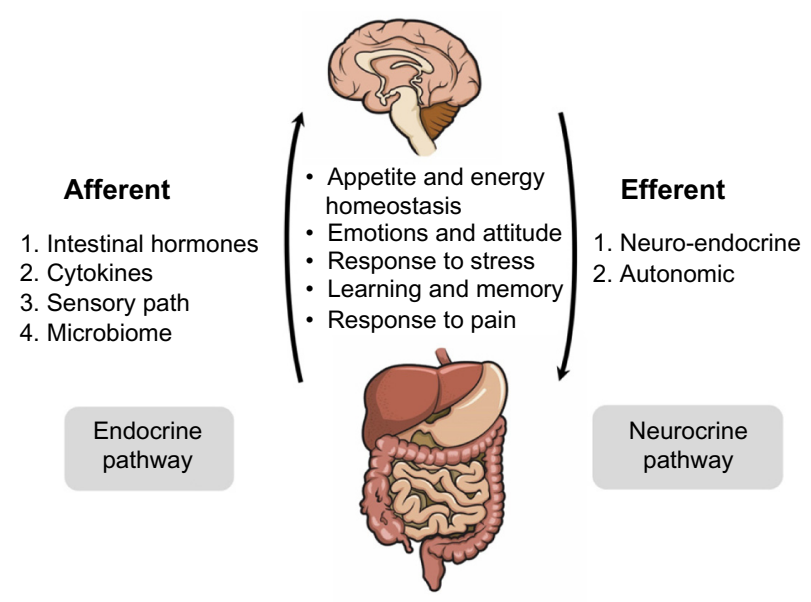

Figure 2 Gut-brain axis.

Note: Bidirectional gut-brain communication includes both afferent and efferent pathways showing the role of different mechanisms involved.

from activity of inflammatory mediators (interleukin-6, tumor necrosis factor, etc). Disruption of the integrity of the BBB allows the entrance of leukocytes/lymphocytes and/or neurotoxins into the brain. ${ }^{93,94}$ Neurotropic viruses as well as bacterial toxins produced in the intestines may reach the CNS via enteroendocrine cells or directly via the vagus nerve which innervates the distal part of the small intestine. ${ }^{95,96}$

\section{Clinical observations and research directions}

Clinical observations revealed significant temporary alleviation of autistic behaviors after antibacterial interventions (treatment by antibiotics such as vancomycin or metronidazole) in children with regressive autism and drew researchers' attention to the possible role of intestinal microbiota changes in the pathogenesis of ASD. ${ }^{97-99}$

The human microbiome is dominated by two phyla, the Firmicutes ( 75\%) and Bacteroidetes ( 20\%), with lesser contributions from Proteobacteria and Actinobacteria. Overgrowth of obligate anaerobic organisms such as Clostridium spp. (Firmicutes), as well as Desulfovibrio spp., and a significant decrease in the Bacteroidetes/ Firmicutes ratio were found in children with autism. ${ }^{95,97,100-102}$ Fermentation end products of dietary fibers, fermentable carbohydrates, and resistant starches, which are not broken down in the upper digestive tract by these anaerobic intestinal microbiota, are short-chain fatty acids (SCFAs) such as propionate, acetate, and butyrate. ${ }^{103}$ Propionic acid and other SCFAs are of particular interest because of their wide range of effects on a host's health and ability to cross GBB and BBB. ${ }^{104,105}$ SCFAs serve as energy substrates for colonocytes, 
modulate colonic $\mathrm{pH}$, regulate colonic cell proliferation and differentiation, and contribute to hepatic gluconeogenesis and cholesterol synthesis. ${ }^{102}$

Propionic acid has been found to be elevated in stool samples or urine of children with autism. ${ }^{106-108}$ Conditions known to be associated with elevated SCFA levels include inherited and acquired conditions such as propionic/methylmalonic acidemia, biotinidase/holocarboxylase deficiency, and mitochondrial disorders. ${ }^{109,110}$ These conditions present with developmental delay, regression, seizure disorders, as well as GI symptoms. ${ }^{111}$ A subset of children with autism with elevated SCFA levels may benefit from a low-carbohydrate diet reducing SCFA production. Williams et al indicated a relationship between human intestinal gene expression and bacterial community structure and may provide insights into the pathophysiology of GI disturbances in children with autism. $^{102}$

A link between microbiota and metabolism may be found in children with autism and hyperoxalemia/hyperoxaluria. ${ }^{112}$ Disorders of oxalate metabolism may be the result of a genetic background (severe hyperoxalemia and hyperoxaluria), increased GI permeability, or decreased intestinal bacterial strains in the microflora participating in oxalate degradation (ie, Oxylobacter formigenes). Disorders of oxalate metabolism may be suspected in those children with food selectivity who strongly avoid eating foods high in oxalates: fruits (strawberries, berries, apples, black grapes, tangerines, kiwis), grains (millet, oats, wheat), or nuts.

The complex relationship between human intestinal gene expression and bacterial community structure provide insights into molecular mechanisms underlying the pathophysiology of GI disturbances in children with autism. ${ }^{113}$ Additional studies on this subject were started in many countries such as in the USA in 2007 with The Human Microbiome Project. Today's knowledge, however, allows for experimental therapeutic use of fecal microbiota transplantation (FMT) (approved by the US Food and Drug Administration in 2013) mainly as a treatment for patients suffering from Clostridium difficile infection (CDI). ${ }^{114}$ Children diagnosed with ASD and $\mathrm{CDI}$ are considered as potential recipients who may benefit from FMT.

\section{Epigenetic role of the microbiota}

Children with autism often have a positive history of complications during prenatal and perinatal periods. The beginning of human life is a crucial period of exposition to factors determining the composition of the intestinal microbiota. Imbalance in a child's intestinal microbiota may be a result of many different factors such as maternal infections during pregnancy, insufficient bacterial colonization due to cesarean section, inadequate nursing with breast milk, infections with pathogenic microbes, antibiotic exposure (during both preand postnatal periods), and consumption of refined foods with little fiber (which act as prebiotics). ${ }^{115}$ An example of postnatal exposure to antibiotics through diet is connected with feeding low doses of antibiotics (termed subtherapeutic antibiotic treatment) to farm animals to increase their rate of growth. ${ }^{116}$ These factors relating to environment/lifestyle and disease state may lead to a reduced or altered intestinal flora with subsequent possible epigenetic modifications (eg, DNA methylation) and finally changes in the phenotype. ${ }^{20,117}$ Heterogeneity of ASD expressed as different endophenotypes may reflect a varied genetic basis as well as exposure to different epigenetic factors in the beginning of life. ${ }^{118}$

\section{Nutritional treatment of children with ASD}

The biological activity of the gut ecosystem closely reflects diet quality, which plays a critical function in the establishment, maturation, and maintenance of microbial diversity. ${ }^{90}$ The microbiome, intestinal epithelial barrier, and dietary intake interact and modulate one another. ${ }^{103}$ Dietetic interventions may ameliorate clinical symptoms in certain children with autism encouraging parents to test out different diets. ${ }^{119}$ However, there is still an insufficient number of randomized research studies on efficiency of dietary interventions as seen with searches yielding single results in the Cochrane Database of Systematic Reviews. ${ }^{120}$ According to a study by Pennesi and Klein, children with ASD treated with an elimination diet may be diet responders and diet nonresponders. ${ }^{119} \mathrm{~A}$ common discussion involves the possible therapeutic effects of eliminating gluten or casein from the diet (casein-free, gluten-free [CFGF] diet). ${ }^{73,84,121,122} \mathrm{~A}$ blinded study by Elder et al evaluated a cycled 12-week elimination diet (CFGF) with a 12-week casein- and gluten-rich diet in a group of 15 children with autism and found no differences in developmental markers or behaviors. ${ }^{122}$ Likewise, a more recent study by Navarro et al did not support an association with gluten and/or milk in the diet and autistic behavior. ${ }^{84}$

On the other hand, Knivsberg et al in a single blind study including ASD children with urinary peptide abnormalities over a period of 1 year observed an improvement in a group of children on a restriction diet (CFGF) as compared to control subjects. ${ }^{123}$ This draws attention to an opioid phenotype of autism linked with diet and food-derived oligopeptides called exorphins. ${ }^{124,125}$ Exorphins are derived from casein 
and/or gluten when proteins are incompletely digested due to decreased activity of the enzyme dipeptidyl peptidase IV..$^{126,127}$ Beta-casomorphin (from casein) and/or gliadomorphin (from gluten) can cross the epithelial monolayer as confirmed using Caco-2 cell monolayers, a model of human intestinal paracellular absorption. ${ }^{128}$ Exogenous opioid peptides may have an influence on GI functions, and after passing the gut barrier, beta-casomorphins may affect functions of the immunological system as well as dopaminergic, serotoninergic, and GABAergic systems in the brain regulating opioid receptor development and elicit behavioral effects. ${ }^{129}$ Decreased perception of pain, constipation, pruritis, stereotypical behavior, a labile affect, decreased social interaction, and disordered development are a potential complex of common symptoms in certain patients with ASD. These signs and symptoms overlap with the biological activity of opioids. This may be associated with high rates of gluten and/or casein exclusion diets. While successful treatment with favorable outcomes (reductions in stereotypical behavior or self-harm, improvement of speech and social interactions) using naltrexone, an opioid receptor antagonist, has been published, the theory still remains to be confirmed in clinical studies. ${ }^{2,124,130,131}$ Analyses of urinary opioids in children with ASD yield conflicting results. ${ }^{132}$ Reichelt and Knivsberg confirmed the existence of hyperpeptiduria, while Dettmer et al, using different analytical techniques (solid phase extraction-high performance liquid chromatography-tandem mass spectrometry), did not detect increased amounts of endorphins (deltorphins 1 and 2) or exorphins (gliadomorphins, $\beta$-casomorphin) in the urine of 56 children with ASD. ${ }^{133,134}$

Current evidence of the efficacy of gluten and/or casein exclusion diets is poor; however, an opioid phenotype of autism has not been dismissed. Large-scale, good-quality randomized controlled trials are needed. ${ }^{120}$ Despite different final results, the authors agree that restrictive diets should be implemented only where a food allergy or food intolerance is detected.

Sensory integration dysfunction and sensory sensitivity result in children with autism commonly having selfrestricted diets with avoidance of food of a particular color or consistency, picky eating, or disordered eating behaviors which may lead to secondary problems with a child's nutritional status. ${ }^{135}$ Studies investigating nutritional quality in children with autism were concisely gathered in a publication by Coury et al. ${ }^{54}$ Recommended dietary allowances of energy, carbohydrates, fats, proteins, and micronutrients may not be met, or levels of one nutrient may be in excess compared to others. ${ }^{135}$ Inadequate intakes of vitamin D, vitamin A, and calcium were more common in children with ASD than in healthy children. ${ }^{136}$ It is recommended that pediatricians routinely monitor anthropometry as part of the evaluation of children with ASD. Primary care nutritional assessment of each person with an ASD should include 1) weight to height or body mass index, 2) weight to age, 3) height to age, and 4) any marked changes in growth rate (percentiles over time). ${ }^{53}$ Treatment with an elimination diet cannot increase the risk of nutritional deficiencies. Complementary and alternative medicine (CAM) commonly used in management of children with ASD should meet the same requirements. CAM therapies often initiated by parents before discussing them with their physician may present with possible adverse side effects if implemented without proper monitoring. ${ }^{137}$ The American Academy of Pediatrics recommends that CAM therapies be discussed in every child with a chronic illness or disability. ${ }^{138}$

\section{Conclusion}

This paper addresses the possible links between ASD and GI disorders, and debated points are summarized in Figure 3.

According to current recommendations, children with ASD are at risk of having alimentary tract disorders. GI symptoms may overlap with ASD core symptoms through different mechanisms. Shared pathogenetic factors and pathophysiological mechanisms may possibly link ASD and GI disturbances as shown by most recent studies. ASD is a genetically determined developmental brain disorder; however, immune dysregulation, GI inflammation, malfunction of the ANS, genetic and metabolic activity of the microbiome, and dietary metabolites may contribute to brain dysfunction and neuroinflammation depending upon individual genetic vulnerability. ASD has a heterogeneous phenotype with different subendophenotypes of which some reflect GI abnormalities. GI disorders in children with ASD may vary greatly in their nature and localization. Due to a clinical endophenotype presenting as comorbidity of ASD and GI disorders, we propose treating this situation as an "overlap syndrome" as summarized in Figure 4.

Practical use of the concept of an overlap syndrome of ASD and GI disorders may help in identifying those children with ASD who suffer from an alimentary tract disease. Unexplained worsening of nonverbal behaviors such as agitation, anxiety, aggression, self-injury, or sleep deprivation should alert caregivers, physicians, and other professionals about this possibility. This may speed up the diagnosis and treatment commencement, and alleviate both GI and ASD symptoms through reducing pain, stress, or discomfort by treating the comorbid disorder. Furthermore, this may also 


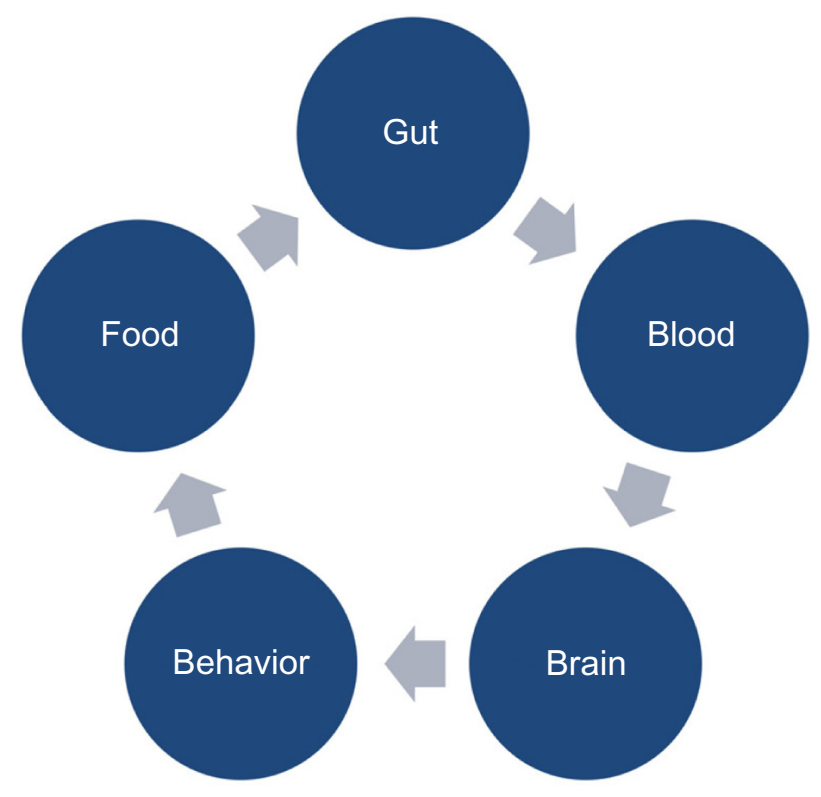

Figure 3 Gut to behavior cycle.

Note: Cycle of pathophysiological influences: gut environment (immunological mucosa barrier integrity, enzymes, microbiome) is reflected in the blood as products of digestion having immunogenic, metabolic, toxic, or biologic opioid activity able to across the blood-brain barrier and influence behavior, subsequent eating behaviors, and food preferences which maintain food selectivity (gut-blood-brain-behaviorfood cycle).

protect children against dietary experiments and restrictions without medical indications.

Our understanding of ASDs has come a long way; however, more work needs to be done in order to determine to what extent are ASD and GI linked with each other. Further studies and more systematic research are warranted.

\section{Acknowledgment}

This paper was a part of an invited lecture presented by Jolanta Wasilewska during a seminar at the RIKEN Brain Science Institute Laboratory for Molecular Psychiatry, Hirosawa, Wako, Japan, on August 22, 2014.

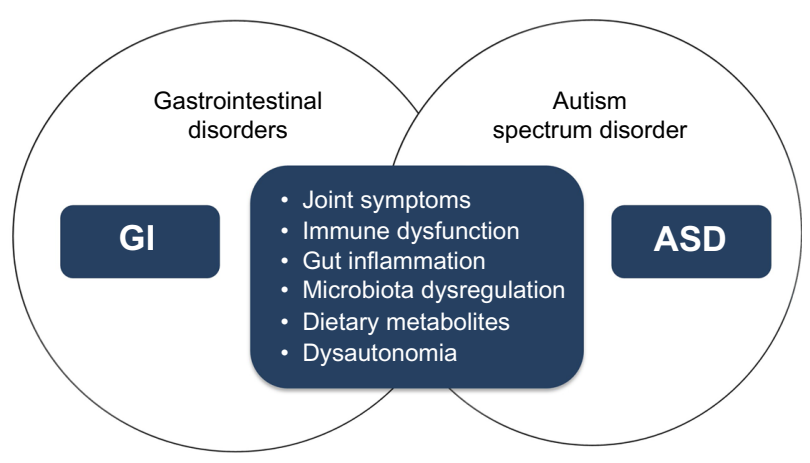

Figure 4 The concept of the overlap syndrome of GI disorders and ASD.

Note: Children with ASD and coexisting Gl disorders are at increased risk of behavior problems, language impairments, affective behaviors, and irritability as well as sleep problems.

Abbreviations: $\mathrm{Gl}$, gastrointestinal; $\mathrm{ASD}$, autism spectrum disorder.

\section{Disclosure}

The authors declare no conflicts of interest in this work.

\section{References}

1. American Psychiatric Association. Diagnostic and Statistical Manual of Mental Disorders. 4th ed. Washington, DC: American Psychiatric Association; 2000. [Text Revision (DSM-IV-TR)].

2. Volkmar F, Siegel M, Woodbury-Smith M, et al. Practice parameter for the assessment and treatment of children and adolescents with autism spectrum disorder. J Am Acad Child Adolesc Psychiatry. 2014;53(2):237-257.

3. Lai MC, Lombardo MV, Baron-Cohen S. Autism. Lancet. 2014; 383(9920):896-910.

4. Muhle R, Trentacoste SV, Rapin I. The genetics of autism. Pediatrics. 2004;113(5):e472-e486.

5. American Psychiatric Association. Diagnostic and Statistical Manual of Mental Disorders. 5th ed. Washington, DC: APA; 2013.

6. Bradstreet JJ, Smith S, Granpeesheh D, El-Dahr JM, Rossignol D. Spironolactone might be a desirable immunologic and hormonal intervention in autism spectrum disorders. Med Hypotheses. 2007; 68(5):979-987.

7. SchneiderT, Przewlocki R. Behavioral alterations in rats prenatally exposed to valproic acid: animal model of autism. Neuropsychopharmacology.2005; 30(1):80-89.

8. The Centers for Disease Control and Prevention (CDC). Autism spectrum disorder prevalence [database on the Internet]; 2014. Available from: http://www.cdc.gov/media/releases/2014/p0327-autismspectrum-disorder.html.

9. Mbadiwe T, Millis RM. Epigenetics and autism. Autism Res Treat. 2013;2013:826156.

10. Goldani AA, Downs SR, Widjaja F, Lawton B, Hendren RL. Biomarkers in autism. Front Psychiatry. 2014;5:100.

11. Hirabayashi Y, Gotoh Y. Epigenetic control of neural precursor cell fate during development. Nat Rev Neurosci. 2010;11(6):377-388.

12. Liu X, Takumi T. Genomic and genetic aspects of autism spectrum disorder. Biochem Biophys Res Commun. 2014;452(2):244-253.

13. Mazina V, Gerdts J, Trinh S, et al. Epigenetics of autism-related impairment: copy number variation and maternal infection.J Dev Behav Pediatr. 2015;36(2):61-67.

14. Goyal DK, Miyan JA. Neuro-immune abnormalities in autism and their relationship with the environment: a variable insult model for autism. Front Endocrinol. 2014;5:29.

15. Koves K, Kausz M, Reser D, Horvath K. What may be the anatomical basis that secretin can improve the mental functions in autism? Regul Pept. 2002;109(1-3):167-172.

16. Shimamoto C, Ohnishi T, Maekawa M, et al. Functional characterization of FABP3, 5 and 7 gene variants identified in schizophrenia and autism spectrum disorder and mouse behavioral studies. Hum Mol Genet. 2015;24(8):2409

17. Anitha A, Nakamura K, Thanseem I, et al. Brain region-specific altered expression and association of mitochondria-related genes in autism. Mol Autism. 2012;3(1):12.

18. Casanova EL, Casanova MF. Genetics studies indicate that neural induction and early neuronal maturation are disturbed in autism. Front Cell Neurosci. 2014;8:397.

19. Korvatska E, Van de Water J, Anders TF, Gershwin ME. Genetic and immunologic considerations in autism. Neurobiol Dis. 2002; 9(2):107-125.

20. Behnia F, Parets SE, Kechichian T, et al. Fetal DNA methylation of autism spectrum disorders candidate genes: association with spontaneous preterm birth. Am J Obstet Gynecol. 2015;212(4):533.e1-533.e9.

21. Yu TW, Chahrour MH, Coulter ME, et al. Using whole-exome sequencing to identify inherited causes of autism. Neuron. 2013;77(2):259-273.

22. Abdelrahman HM, Sherief LM, Alghobashy AA, et al. Association of 5-HT2A receptor gene polymorphisms with gastrointestinal disorders in Egyptian children with autistic disorder. Res Dev Disabil. 2014;36C:485-490. 
23. Zafeiriou DI, Ververi A, Vargiami E. Childhood autism and associated comorbidities. Brain Dev. 2007;29(5):257-272.

24. Heil KM, Schaaf CP. The genetics of autism spectrum disorders a guide for clinicians. Curr Psychiatry Rep. 2013;15(1):334.

25. Carter MT, Scherer SW. Autism spectrum disorder in the genetics clinic: a review. Clin Genet. 2013;83(5):399-407.

26. Kanner L. Autistic disturbances of affective contact. Nerv Child. $1943 ; 2: 217-250$.

27. Jyonouchi H. Autism spectrum disorders and allergy: observation from a pediatric allergy/immunology clinic. Expert Rev Clin Immunol. 2010;6(3):397-411.

28. Wasilewska J, Kaczmarski M, Stasiak-Barmuta A, Tobolczyk J, Kowalewska E. Low serum IgA and increased expression of CD23 on B lymphocytes in peripheral blood in children with regressive autism aged 3-6 years old. Arch Med Sci. 2012;8(2):324-331.

29. Mostafa GA, Al Shehab A, Fouad NR. Frequency of CD4+CD25 high regulatory $\mathrm{T}$ cells in the peripheral blood of Egyptian children with autism. J Child Neurol. 2010;25(3):328-335.

30. Buie T, Campbell DB, Fuchs GJ 3rd, et al. Evaluation, diagnosis, and treatment of gastrointestinal disorders in individuals with ASDs: a consensus report. Pediatrics. 2010;125(Suppl 1):S1-S18.

31. McElhanon BO, McCracken C, Karpen S, Sharp WG. Gastrointestinal symptoms in autism spectrum disorder: a meta-analysis. Pediatrics. 2014;133(5):872-883.

32. Black C, Kaye JA, Jick H. Relation of childhood gastrointestinal disorders to autism: nested case-control study using data from the UK General Practice Research Database. BMJ. 2002;325(7361):419-421.

33. Molloy CA, Manning-Courtney P. Prevalence of chronic gastrointestinal symptoms in children with autism and autistic spectrum disorders. Autism. 2003;7(2):165-171.

34. Horvath K, Perman JA. Autistic disorder and gastrointestinal disease. Curr Opin Pediatr. 2002;14(5):583-587.

35. Kuddo T, Nelson KB. How common are gastrointestinal disorders in children with autism? Curr Opin Pediatr. 2003;15(3):339-343.

36. Levy SE, Souders MC, Ittenbach RF, Giarelli E, Mulberg AE, Pinto-Martin JA. Relationship of dietary intake to gastrointestinal symptoms in children with autistic spectrum disorders. Biol Psychiatry. 2007;61(4):492-497.

37. Horvath K, Perman JA. Autism and gastrointestinal symptoms. Curr Gastroenterol Rep. 2002;4(3):251-258.

38. Afzal N, Murch S, Thirrupathy K, Berger L, Fagbemi A, Heuschkel R. Constipation with acquired megarectum in children with autism. Pediatrics. 2003;112(4):939-942.

39. Fasano A, Sapone A, Zevallos V, Schuppan D. Nonceliac gluten sensitivity. Gastroenterology. 2015;166(4):805-811.

40. Catassi C, Bai JC, Bonaz B, et al. Non-celiac gluten sensitivity: the new frontier of gluten related disorders. Nutrients. 2013;5(10):3839-3853.

41. Horvath K, Papadimitriou JC, Rabsztyn A, Drachenberg C, Tildon JT. Gastrointestinal abnormalities in children with autistic disorder. J Pediatr. 1999;135(5):559-563.

42. Delgado-Aros S, Camilleri M. Visceral hypersensitivity. J Clin Gastroenterol. 2005;39(5 Suppl 3):S194-S203. [discussion S10].

43. Axelrod FB, Chelimsky GG, Weese-Mayer DE. Pediatric autonomic disorders. Pediatrics. 2006;118(1):309-321.

44. Lonsdale D, Shamberger RJ, Obrenovich ME. Dysautonomia in autism spectrum disorder: case reports of a family with review of the literature. Autism Res Treat. 2011;2011:129795.

45. Hirstein W, Iversen P, Ramachandran VS. Autonomic responses of autistic children to people and objects. Proc Biol Sci. 2001;268(1479): $1883-1888$

46. Maenner MJ, Arneson CL, Levy SE, Kirby RS, Nicholas JS, Durkin MS. Brief report: association between behavioral features and gastrointestinal problems among children with autism spectrum disorder. J Autism Dev Disord. 2012;42(7):1520-1525.

47. Gorrindo P, Williams KC, Lee EB, Walker LS, McGrew SG, Levitt P. Gastrointestinal dysfunction in autism: parental report, clinical evaluation, and associated factors. Autism Res. 2012;5(2):101-108.
48. Mazefsky CA, Schreiber DR, Olino TM, Minshew NJ. The association between emotional and behavioral problems and gastrointestinal symptoms among children with high-functioning autism. Autism. 2013; 18(5):493-501.

49. Mouridsen SE, Isager T, Rich B. Diseases of the gastrointestinal tract in individuals diagnosed as children with atypical autism: a Danish register study based on hospital diagnoses. Autism. 2013;17(1):55-63.

50. Smith RA, Farnworth H, Wright B, Allgar V. Are there more bowel symptoms in children with autism compared to normal children and children with other developmental and neurological disorders? A case control study. Autism. 2009;13(4):343-355.

51. Schreck KA, Williams K, Smith AF. A comparison of eating behaviors between children with and without autism. JAutism Dev Disord. 2004; 34(4):433-438.

52. Mirescu C, Peters JD, Noiman L, Gould E. Sleep deprivation inhibits adult neurogenesis in the hippocampus by elevating glucocorticoids. Proc Natl Acad Sci U S A. 2006;103(50):19170-19175.

53. Buie T, Fuchs GJ 3rd, Furuta GT, Kooros K, Levy J, Lewis JD, et al. Recommendations for evaluation and treatment of common gastrointestinal problems in children with ASDs. Pediatrics. 2010 January;125 Suppl 1: S19-29.

54. Coury DL, Ashwood P, Fasano A, et al. Gastrointestinal conditions in children with autism spectrum disorder: developing a research agenda. Pediatrics. 2012;130(Suppl 2):S160-S168.

55. Brown AC, Mehl-Madrona L. Autoimmune and gastrointestinal dysfunctions: does a subset of children with autism reveal a broader connection? Expert Rev Gastroenterol Hepatol. 2011;5(4):465-477.

56. Walker SJ, Fortunato J, Gonzalez LG, Krigsman A. Identification of unique gene expression profile in children with regressive autism spectrum disorder (ASD) and ileocolitis. PLoS One. 2013;8(3):e58058.

57. Fernell E, Fagerberg UL, Hellstrom PM. No evidence for a clear link between active intestinal inflammation and autism based on analyses of faecal calprotectin and rectal nitric oxide. Acta Paediatr. 2007;96(7): 1076-1079.

58. Kokkonen J, Karttunen TJ. Lymphonodular hyperplasia on the mucosa of the lower gastrointestinal tract in children: an indication of enhanced immune response? J Pediatr Gastroenterol Nutr. 2002; $34(1): 42-46$

59. Turunen S, Karttunen TJ, Kokkonen J. Lymphoid nodular hyperplasia and cow's milk hypersensitivity in children with chronic constipation. J Pediatr. 2004;145(5):606-611.

60. Sicherer SH, Eigenmann PA, Sampson HA. Clinical features of food protein-induced enterocolitis syndrome. J Pediatr. 1998;133(2): 214-219.

61. Nowak-Wegrzyn A, Sampson HA, Wood RA, Sicherer SH. Food protein-induced enterocolitis syndrome caused by solid food proteins. Pediatrics. 2003;111(4 pt 1):829-835.

62. Muraro A, Werfel T, Hoffmann-Sommergruber K, et al. EAACI food allergy and anaphylaxis guidelines: diagnosis and management of food allergy. Allergy. 2014;69(8):1008-1025.

63. Soares-Weiser K, Takwoingi Y, Panesar SS, et al. The diagnosis of food allergy: a systematic review and meta-analysis. Allergy. 2014; 69(1):76-86.

64. Canonica GW, Ansotegui IJ, Pawankar R, et al. A WAO - ARIA GA(2)LEN consensus document on molecular-based allergy diagnostics. World Allergy Organ J. 2013;6(1):17.

65. Castellani ML, Conti CM, Kempuraj DJ, et al. Autism and immunity: revisited study. Int J Immunopathol Pharmacol. 2009;22(1):15-19.

66. Ashwood P, Anthony A, Pellicer AA, Torrente F, Walker-Smith JA, Wakefield AJ. Intestinal lymphocyte populations in children with regressive autism: evidence for extensive mucosal immunopathology. J Clin Immunol. 2003 November;23(6):504-517.

67. Papadopoulou A, Koletzko S, Heuschkel R, et al. Management guidelines of eosinophilic esophagitis in childhood. J Pediatr Gastroenterol Nutr. 2014;58(1):107-118.

68. Dellon ES. Eosinophilic esophagitis. Gastroenterol Clin North Am. 2013;42(1):133-153. 
69. Jarocka-Cyrta E, Wasilewska J, Kaczmarski MG. Brief report: eosinophilic esophagitis as a cause of feeding problems in autistic boy. The first reported case. J Autism Dev Disord. 2010;41(3):372-374.

70. Anderson SE, Must A, Curtin C, Bandini LG. Meals in our household: reliability and initial validation of a questionnaire to assess child mealtime behaviors and family mealtime environments. J Acad Nutr Diet. 2012;112(2):276-284

71. Buie T. The relationship of autism and gluten. Clin Ther. 2013;35(5): 578-583.

72. Klein S, Sharifi-Hannauer P, Martinez-Agosto JA. Macrocephaly as a clinical indicator of genetic subtypes in autism. Autism Res. 2013; 6(1):51-56.

73. Lau NM, Green PH, Taylor AK, et al. Markers of celiac disease and gluten sensitivity in children with autism. PLoS One. 2013;8(6):e66155.

74. Stamnaes J, Dorum S, Fleckenstein B, Aeschlimann D, Sollid LM. Gluten T cell epitope targeting by TG3 and TG6; implications for dermatitis herpetiformis and gluten ataxia. Amino Acids. 2010;39(5): 1183-1191.

75. Iannaccone M, Titta F, Serretiello E, Monfregola M, Gentile V. Possible physiopathological effects of the transglutaminase activity on the molecular mechanisms responsible for human neurodegenerative diseases. Recent Pat CNS Drug Discov. 2014;9(2):76-84.

76. Cascella NG, Santora D, Gregory P, Kelly DL, Fasano A, Eaton WW. Increased prevalence of transglutaminase 6 antibodies in sera from schizophrenia patients. Schizophr Bull. 2013;39(4):867-871.

77. de Magistris L, Familiari V, Pascotto A, et al. Alterations of the intestinal barrier in patients with autism spectrum disorders and in their firstdegree relatives. J Pediatr Gastroenterol Nutr. 2010;51(4): 418-424.

78. Ader R, Cohen N, Felten DL. Brain, behavior, and immunity. Brain Behav Immun. 1987;1(1):1-6.

79. Goines P, Van de Water J. The immune system's role in the biology of autism. Curr Opin Neurol. 2010;23(2):111-117.

80. Liu Z, Li N, Neu J. Tight junctions, leaky intestines, and pediatric diseases. Acta Paediatr. 2005;94(4):386-393.

81. Buhner S, Buning C, Genschel J, et al. Genetic basis for increased intestinal permeability in families with Crohn's disease: role of CARD15 3020insC mutation? Gut. 2006;55(3):342-347.

82. Zareie M, Johnson-Henry K, Jury J, et al. Probiotics prevent bacterial translocation and improve intestinal barrier function in rats following chronic psychological stress. Gut. 2006;55(11):1553-1560.

83. D'Eufemia P, Celli M, Finocchiaro R, et al. Abnormal intestinal permeability in children with autism. Acta Paediatr. 1996;85(9):1076-1079.

84. Navarro F, Pearson DA, Fatheree N, Mansour R, Hashmi SS, Rhoads JM. Are 'leaky gut' and behavior associated with gluten and dairy containing diet in children with autism spectrum disorders? Nutr Neurosci. 2015;18(4):177-185.

85. Kendall A. Some observations on the study of the intestinal bacteria. J Biol Chem. 1909;6:499-507.

86. Mayer EA, Tillisch K, Gupta A. Gut/brain axis and the microbiota. J Clin Invest. 2015;125(3):926-938.

87. Stilling RM, Dinan TG, Cryan JF. Microbial genes, brain and behaviour - epigenetic regulation of the gut-brain axis. Genes Brain Behav. 2014;13(1):69-86.

88. Severance EG, Prandowszky E, Castilione J, Yolken RH. Gastroenterology issues in schizophrenia: why the gut matters. Curr Psychiatr Rep. 2015;17(5):27.

89. Douglas-Escobar M, Elliott E, Neu J. Effect of intestinal microbial ecology on the developing brain. JAMA Pediatrics. 2013; 167(4):374-379.

90. Mulle JG, Sharp WG, Cubells JF. The gut microbiome: a new frontier in autism research. Curr Psychiatry Rep. 2013;15(2):337.

91. Heberling CA, Dhurjati PS, Sasser M. Hypothesis for a systems connectivity model of autism spectrum disorder pathogenesis: links to gut bacteria, oxidative stress, and intestinal permeability. Med Hypotheses. 2013;80(3):264-270

92. Kraneveld AD, de Theije CG, van Heesch F, et al. The neuro-immune axis: prospect for novel treatments for mental disorders. Basic Clin Pharmacol Toxicol. 2014;114(1):128-136.
93. Angelidou A, Asadi S, Alysandratos KD, Karagkouni A, Kourembanas S, Theoharides TC. Perinatal stress, brain inflammation and risk of autismreview and proposal. BMC Pediatr. 2012;12:89.

94. Theoharides TC, Zhang B. Neuro-inflammation, blood-brain barrier, seizures and autism. $J$ Neuroinflammation. 2011;8:168.

95. Bolte ER. Autism and Clostridium tetani. Med Hypotheses. 1998; 51(2):133-144

96. Bohorquez DV, Shahid RA, Erdmann A, et al. Neuroepithelial circuit formed by innervation of sensory enteroendocrine cells. J Clin Invest. 2015;125(2):782-786

97. Sandler RH, Finegold SM, Bolte ER, et al. Short-term benefit from oral vancomycin treatment of regressive-onset autism. J Child Neurol. 2000;15(7):429-435.

98. Finegold SM, Dowd SE, Gontcharova V, et al. Pyrosequencing study of fecal microflora of autistic and control children. Anaerobe. 2010;16(4):444-453.

99. Critchfield JW, van Hemert S, Ash M, Mulder L, Ashwood P. The potential role of probiotics in the management of childhood autism spectrum disorders. Gastroenterol Res Pract. 2011;2011:161358.

100. Tomova A, Husarova V, Lakatosova S, et al. Gastrointestinal microbiota in children with autism in Slovakia. Physiol Behav. 2015;138: 179-187.

101. Finegold SM. State of the art; microbiology in health and disease. Intestinal bacterial flora in autism. Anaerobe. 2011;17(6): 367-368.

102. Ecker C, Suckling J, Deoni SC, et al. Brain anatomy and its relationship to behavior in adults with autism spectrum disorder: a multicenter magnetic resonance imaging study. Arch Gen Psychiatry. 2012;69(2):195-209

103. Guzman JR, Conlin VS, Jobin C. Diet, microbiome, and the intestinal epithelium: an essential triumvirate? Biomed Res Int. 2013; 2013:425146.

104. Karuri AR, Dobrowsky E, Tannock IF. Selective cellular acidification and toxicity of weak organic acids in an acidic microenvironment. $\mathrm{Br}$ J Cancer. 1993;68(6):1080-1087.

105. Adams JB, Johansen LJ, Powell LD, Quig D, Rubin RA. Gastrointestinal flora and gastrointestinal status in children with autism comparisons to typical children and correlation with autism severity. BMC Gastroenterol. 2011;11:22

106. Macfabe DF. Short-chain fatty acid fermentation products of the gut microbiome: implications in autism spectrum disorders. Microb Ecol Health Dis. 2012;23.

107. Wang L, Christophersen CT, Sorich MJ, Gerber JP, Angley MT, Conlon MA. Elevated fecal short chain fatty acid and ammonia concentrations in children with autism spectrum disorder. Dig Dis Sci. 2012;57(8):2096-2102.

108. Shaw W. Increased urinary excretion of a 3-(3-hydroxyphenyl)3-hydroxypropionic acid (HPHPA), an abnormal phenylalanine metabolite of Clostridia spp. in the gastrointestinal tract, in urine samples from patients with autism and schizophrenia. Nutr Neurosci. 2010;13(3):135-143.

109. Rossignol DA, Frye RE. Evidence linking oxidative stress, mitochondrial dysfunction, and inflammation in the brain of individuals with autism. Front Physiol. 2014;5:150

110. Schreiber J, Chapman KA, Summar ML, et al. Neurologic considerations in propionic acidemia. Mol Genet Metab. 2012;105(1): $10-15$.

111. Al-Owain M, Kaya N, Al-Shamrani H, et al. Autism spectrum disorder in a child with propionic acidemia. JIMD Rep. 2013;7:63-66

112. Konstantynowicz J, Porowski T, Zoch-Zwierz W, et al. A potential pathogenic role of oxalate in autism. Eur J Paediatr Neurol. 2012;16(5):485-491.

113. Cao X, Lin P, Jiang P, Li C. Characteristics of the gastrointestinal microbiome in children with autism spectrum disorder: a systematic review. Shanghai Arch Psychiatry. 2013;25(6):342-353.

114. Aroniadis OC, Brandt LJ. Fecal microbiota transplantation: past, present and future. Curr Opin Gastroenterol. 2013;29(1):79-84. 
115. Toh MC, Allen-Vercoe E. The human gut microbiota with reference to autism spectrum disorder: considering the whole as more than a sum of its parts. Microb Ecol Health Dis. 2015;26:26309.

116. Blaser MJ, Falkow S. What are the consequences of the disappearing human microbiota? Nature Rev Microbiol. 2009;7(12):887-894.

117. Grafodatskaya D, Chung B, Szatmari P, Weksberg R. Autism spectrum disorders and epigenetics. J Am Acad Child Adolesc Psychiatry. 2010;49(8):794-809.

118. Flashner BM, Russo ME, Boileau JE, Leong DW, Gallicano GI. Epigenetic factors and autism spectrum disorders. Neuromolecular Med. 2013;15(2):339-350.

119. Pennesi CM, Klein LC. Effectiveness of the gluten-free, casein-free diet for children diagnosed with autism spectrum disorder: based on parental report. Nutr Neurosci. 2012;15(2):85-91.

120. Adams SJ, Burton N, Cutress A, et al. Development of double blind gluten and casein free test foods for use in an autism dietary trial. J Hum Nutr Diet. 2008;21(4):374.

121. Whiteley P, Shattock P, Knivsberg AM, et al. Gluten- and casein-free dietary intervention for autism spectrum conditions. Front Hum Neurosci. 2012;6:344.

122. Elder JH, Shankar M, Shuster J, Theriaque D, Burns S, Sherrill L. The gluten-free, casein-free diet in autism: results of a preliminary double blind clinical trial. J Autism Dev Disord. 2006;36(3):413-420.

123. Knivsberg AM, Reichelt KL, Hoien T, Nodland M. A randomised, controlled study of dietary intervention in autistic syndromes. Nutr Neurosci. 2002;5(4):251-261.

124. Leboyer M, Bouvard MP, Launay JM, et al. Une hypothese opiacee dans l'autisme infantile? Essais therapeutiques avec la naltrexone [Opiate hypothesis in infantile autism? Therapeutic trials with naltrexone]. Encephale. 1993;19(2):95-102. French.

125. Sahley TL, Panksepp J. Brain opioids and autism: an updated analysis of possible linkages. J Autism Dev Disord. 1987;17(2):201-216.

126. Trivedi MS, Shah JS, Al-Mughairy S, et al. Food-derived opioid peptides inhibit cysteine uptake with redox and epigenetic consequences. J Nutr Biochem. 2014;25(10):1011-1018.

127. Johnson B, Ulberg S, Shivale S, Donaldson J, Milczarski B, Faraone SV. Fibromyalgia, autism, and opioid addiction as natural and induced disorders of the endogenous opioid hormonal system. Discov Med. 2014;18(99):209-220.
128. Klionsky DJ, Abdalla FC, Abeliovich H, et al. Guidelines for the use and interpretation of assays for monitoring autophagy. Autophagy. 2012;8(4):445-544.

129. Cieslinska A, Sienkiewicz-Szlapka E, Wasilewska J, et al. Influence of candidate polymorphisms on the dipeptidyl peptidase IV and muopioid receptor genes expression in aspect of the beta-casomorphin-7 modulation functions in autism. Peptides. 2015;65C:6-11.

130. Leboyer M, Bouvard MP, Launay JM, et al. Brief report: a doubleblind study of naltrexone in infantile autism. J Autism Dev Disord. 1992;22(2):309-319.

131. Woodard C, Groden J, Goodwin M, Bodfish J. A placebo double-blind pilot study of dextromethorphan for problematic behaviors in children with autism. Autism. 2007;11(1):29-41.

132. Cass H, Gringras P, March J, et al. Absence of urinary opioid peptides in children with autism. Arch Dis Child. 2008;93(9):745-750.

133. Reichelt KL, Knivsberg AM. Can the pathophysiology of autism be explained by the nature of the discovered urine peptides? Nutr Neurosci. 2003;6(1):19-28.

134. Dettmer K, Hanna D, Whetstone P, Hansen R, Hammock BD. Autism and urinary exogenous neuropeptides: development of an on-line SPEHPLC-tandem mass spectrometry method to test the opioid excess theory. Anal Bioanal Chem. 2007;388(8):1643-1651.

135. Kral TV, Eriksen WT, Souders MC, Pinto-Martin JA. Eating behaviors, diet quality, and gastrointestinal symptoms in children with autism spectrum disorders: a brief review. J Pediatr Nurs. 2013;28(6):548-556.

136. Bandini LG, Anderson SE, Curtin C, et al. Food selectivity in children with autism spectrum disorders and typically developing children. J Pediatr. 2010;157(2):259-264.

137. Akins RS, Angkustsiri K, Hansen RL. Complementary and alternative medicine in autism: an evidence-based approach to negotiating safe and efficacious interventions with families. Neurotherapeutics. 2010; 7(3):307-319.

138. Committee on Children with Disabilities. American Academy of Pediatrics: counseling families who choose complementary and alternative medicine for their child with chronic illness or disability. Pediatrics. 2001;107(3):598-601.
Pediatric Health, Medicine and Therapeutics

\section{Publish your work in this journal}

Pediatric Health, Medicine and Therapeutics is an international, peerreviewed, open access journal publishing original research, reports, editorials, reviews and commentaries. All aspects of health maintenance, preventative measures and disease treatment interventions are addressed within the journal. Practitioners from all disciplines are invited to submit

\section{Dovepress}

their work as well as healthcare researchers and patient support groups. The manuscript management system is completely online and includes a very quick and fair peer-review system. Visit http://www.dovepress.com/ testimonials.php to read real quotes from published authors. 